UMTRI-2005-19

\title{
EFFECTIVENESS OF CLEAR-LENS TURN SIGNALS \\ IN DIRECT SUNLIGHT
}

\author{
Michael Sivak \\ Brandon Schoettle \\ Michael J. Flannagan \\ Takako Minoda
}

July 2005 


\title{
EFFECTIVENESS OF CLEAR-LENS TURN SIGNALS IN DIRECT SUNLIGHT
}

\author{
Michael Sivak \\ Brandon Schoettle \\ Michael J. Flannagan \\ Takako Minoda
}

The University of Michigan

Transportation Research Institute

Ann Arbor, Michigan 48109-2150

U.S.A.

Report No. UMTRI-2005-19

July 2005 
Technical Report Documentation Page

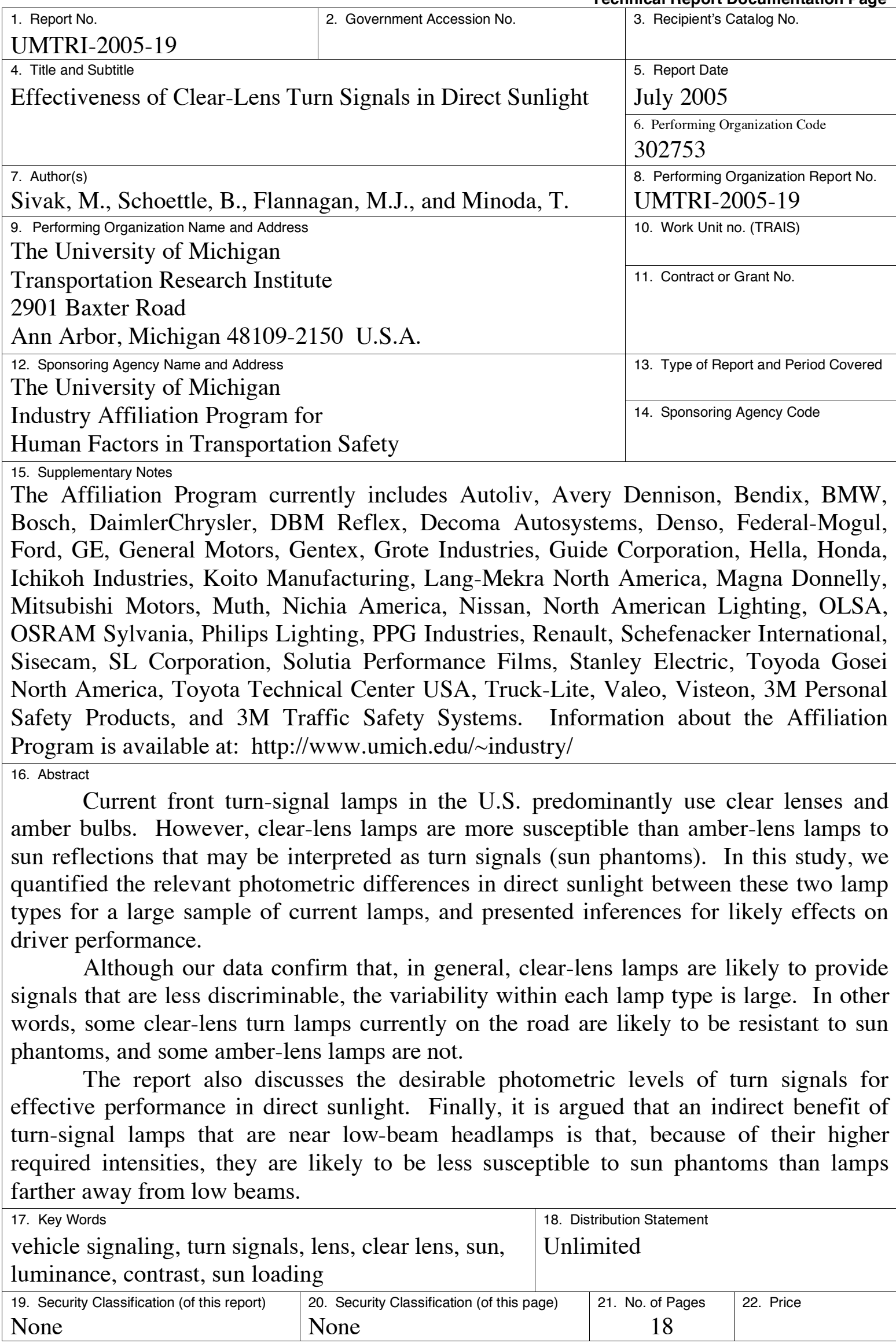




\section{Acknowledgment}

Appreciation is extended to the members of the University of Michigan Industry Affiliation Program for Human Factors in Transportation Safety for support of this research. The current members of the Program are:

\begin{tabular}{|c|c|}
\hline Autoliv & Mitsubishi Motors \\
\hline Avery Dennison & Muth \\
\hline Bendix & Nichia America \\
\hline BMW & Nissan \\
\hline Bosch & North American Lighting \\
\hline DaimlerChrysler & OLSA \\
\hline DBM Reflex & OSRAM Sylvania \\
\hline Decoma Autosystems & Philips Lighting \\
\hline Denso & PPG Industries \\
\hline Federal-Mogul & Renault \\
\hline Ford & Schefenacker International \\
\hline GE & Sisecam \\
\hline General Motors & SL Corporation \\
\hline Gentex & Solutia Performance Films \\
\hline Grote Industries & Stanley Electric \\
\hline Guide Corporation & Toyoda Gosei North America \\
\hline Hella & Toyota Technical Center, USA \\
\hline Honda & Truck-Lite \\
\hline Ichikoh Industries & Valeo \\
\hline Koito Manufacturing & Visteon \\
\hline Lang-Mekra North America & 3M Personal Safety Products \\
\hline Magna Donnelly & 3M Traffic Safety Systems \\
\hline
\end{tabular}




\section{Contents}

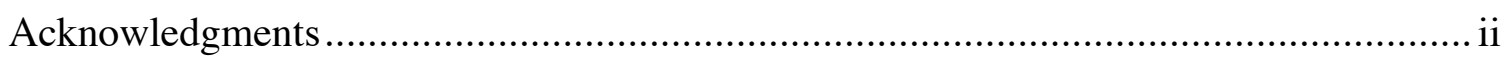

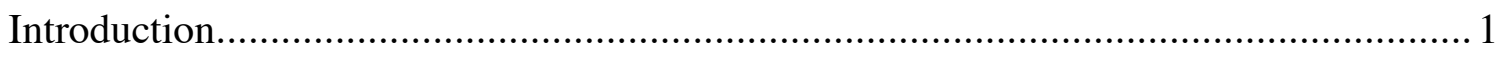

Current construction of front turn-signal lamps in the U.S. ................................ 3

Photometric performance of front turn-signal lamps .............................................. 4

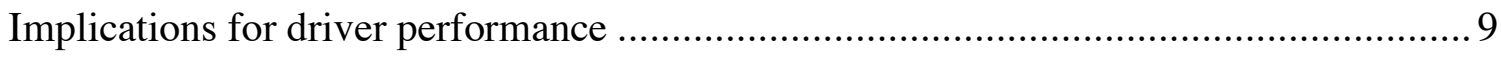

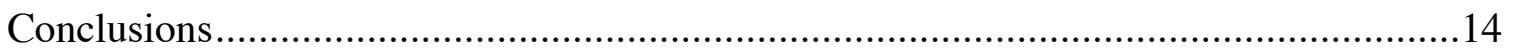

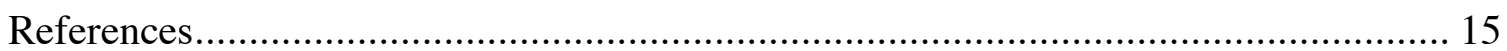




\section{Introduction}

The desired color of an incandescent turn signal can be achieved by the use of a colored material either in a bulb, in a shield (a cap) surrounding the bulb, or in a lens (either an outer lens or an inner lens in combination with a clear outer lens). (See Figure 1 for a schematic diagram of a turn-signal lamp.)

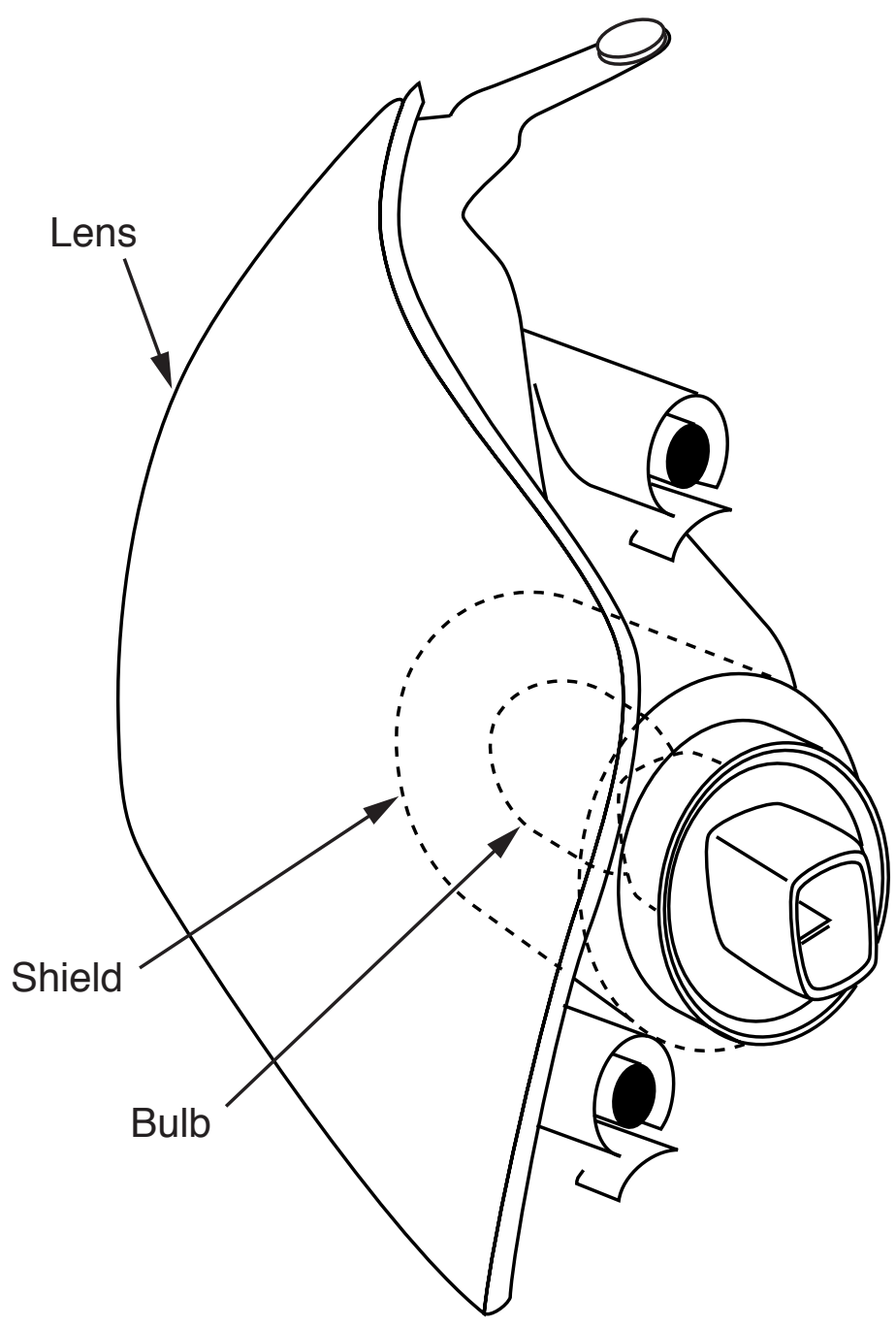

Figure 1. A schematic diagram of a turn signal. (This diagram shows a lamp without an inner lens; in a lamp with both an outer lens and an inner lens the two lenses are usually parallel and adjacent to one other.) 
The appearance of a signal lamp in bright, sunny conditions is influenced by a variety of factors, including the color of the lens, optical structure of the lens, optical structure of the reflector, positioning of the bulb, sun angle, and observation angle. The color of the lens is important because the sunlight passes through the lens twice: first on its way into the cavity of the lamp, and then on its way out of the lamp (after one or more reflections inside the cavity). In contrast, not all of the sunlight will pass twice through a shield or a bulb. (The actual proportion will be influenced by the optical structure of the lens, the location of the shield and the bulb with respect to the optical focus of the lamp, and the relative sizes of the lens, shield, and bulb.) Consequently, more incident sunlight will be filtered out by a lamp with a colored lens than a lamp with a clear lens.

In the first study in this series (Sivak, Flannagan, Kojima, and Traube, 1998), we measured, under bright, sunny conditions, both luminance contrast and color contrast between the on and off states for three identical turn signal lamps that differed only by having the amber pigment in the lens, bulb, or shield (the latter two being clear-lens lamps). The results indicated that, as expected, luminance contrast between the on and off states was greatest for lamps using an amber lens. On the other hand, the results indicated that color contrast between the on and off states favored the lamps using a clear lens.

The reduced luminance contrast for clear-lens lamps in direct sunlight might lead to increased difficulties in discerning whether the signal is on. (This is sometimes referred to as a "sun phantom.") Consequently, our follow-up study (Sullivan and Flannagan, 2001) compared the reaction time of drivers to the same three signal lamps that were photometered in Sivak et al. (1998). The results showed that luminance contrast is the primary characteristic influencing driver performance, and that no compensatory advantage appears to be obtained with increases in color contrast of the magnitude present for the clear-lens lamps.

The present study was designed to evaluate the luminance contrasts for a large number of current turn-signal lamps of different construction and to relate the obtained contrasts to likely effects on driver performance. Of secondary interest was obtaining normative data on the current prevalence of front clear-lens turn signals. 


\section{Current construction of front turn-signal lamps in the U.S.}

\section{Method}

The sample consisted of 20 turn-signal lamps. All lamps were for model year 2004 vehicles. All were left-side (driver-side), front turn-signal lamps manufactured for use on the 20 best-selling passenger vehicles in the U.S. for calendar year 2003 (Automotive News, 2004). These vehicles, in descending order of sales, were Ford FSeries, Chevrolet Silverado, Dodge Ram Pickup, Toyota Camry, Honda Accord, Ford Explorer, Ford Taurus, Honda Civic, Chevrolet Impala, Chevrolet TrailBlazer, Toyota Corolla, Chevrolet Cavalier, Dodge Caravan, Ford Focus, Ford Ranger, Jeep Grand Cherokee, Nissan Altima, Chevrolet Tahoe, GMC Sierra, and Ford Expedition. These 20 vehicles constituted 39\% of all passenger vehicles sold in the U.S. in 2003 (Automotive News, 2004). The lamps were purchased at dealerships in Ann Arbor, Michigan.

\section{Results}

A breakdown of the 20 lamps evaluated by the type of outer lens and the presence/absence of lens optics is shown in Table 1. Also included in Table 1 is a market-weighted breakdown that takes into account the sales figures for the individual vehicles (Automotive News, 2004). These results indicate that clear outer lenses in front turn-signal lamps were used in $80 \%$ of the vehicle models, and comprised $83 \%$ of the sales for these 20 vehicles. All of the clear-lens lamps used an amber bulb. (In other words, none used a clear bulb paired with an amber inner lens or an amber inner shield.)

Table 1

Percentages of front turn signal lamps by lamp type.

\begin{tabular}{|l|c|c|}
\hline \multicolumn{1}{|c|}{ Lamp type } & $\begin{array}{c}\text { Percentage for the } \\
\text { 20 lamps tested }\end{array}$ & $\begin{array}{c}\text { Market-weighted } \\
\text { percentage for the sales of } \\
\text { the 20 model vehicles }\end{array}$ \\
\hline \hline Amber lens, lens optics & 20.0 & 16.7 \\
\hline Clear lens, lens optics & 45.0 & 55.7 \\
\hline Clear lens, no lens optics & 35.0 & 27.6 \\
\hline
\end{tabular}




\section{Photometric performance of front turn-signal lamps}

\section{Method}

Approach. A Photo Research PR-650 spectrophotometer was used to directly measure the luminance of each turn-signal lamp in three conditions (see Table 2). The measurements for the two conditions with the bulb off were taken outdoors, under bright, sunny conditions, while the measurement with the bulb on was performed in a dark lab.

Based on the direct measurements in Table 2, we obtained derived luminances that were used in all subsequent analyses. These derived luminances are described in Table 3.

Table 2

The three directly measured luminances taken for each turn-signal lamp. "Sun on/off" indicates whether a mirror was used to reflect the sun's rays onto the lamp surface. (See text for details.)

\begin{tabular}{|c|c|c|c|}
\hline Condition & Sun & Bulb & Test location \\
\hline \hline A & Off & Off & Outdoors \\
\hline B & On & Off & Outdoors \\
\hline C & Off & On & Lab \\
\hline
\end{tabular}

Table 3

The derived luminances used in all analyses.

\begin{tabular}{|c|c|c|c|}
\hline Condition & Sun & Bulb & $\begin{array}{c}\text { Relationship to the } \\
\text { conditions in Table 2 }\end{array}$ \\
\hline \hline 1 & Off & Off & A \\
\hline 2 & On & Off & B \\
\hline 3 & Off & On & A + C \\
\hline 4 & On & On & B + C \\
\hline
\end{tabular}


Procedure. A schematic diagram of the experimental setup for the outdoor measurements is shown in Figure 2. A mirror $(30 \mathrm{~cm}$ by $30 \mathrm{~cm})$ was used to reflect bright sunlight into each test lamp. The mirror was positioned so that the sun angle to each lamp was $5^{\circ}$ left and $5^{\circ}$ up, simulating a reasonably worst-case scenario.

The position of the photometer was adjusted to record the average luminance of the light-emitting surface and immediately surrounding surfaces of each lamp as seen from $\mathrm{H}, \mathrm{V}$ (the optical axis of the lamp). The distance between the photometer and the lamp was $10 \mathrm{~m}$. The photometer aperture was $1^{\circ}$, and it covered the entire light-emitting surface of each lamp, as well as some adjacent surfaces. The area covered by the $1^{\circ}$ aperture at the viewing distance of $10 \mathrm{~m}$ corresponds to $0.5^{\circ}$ (a reasonable integration area for vision) across an intersection at a distance of $20 \mathrm{~m}$. (The indoor measurements used the same geometric relationship between the photometer and the lamp.)
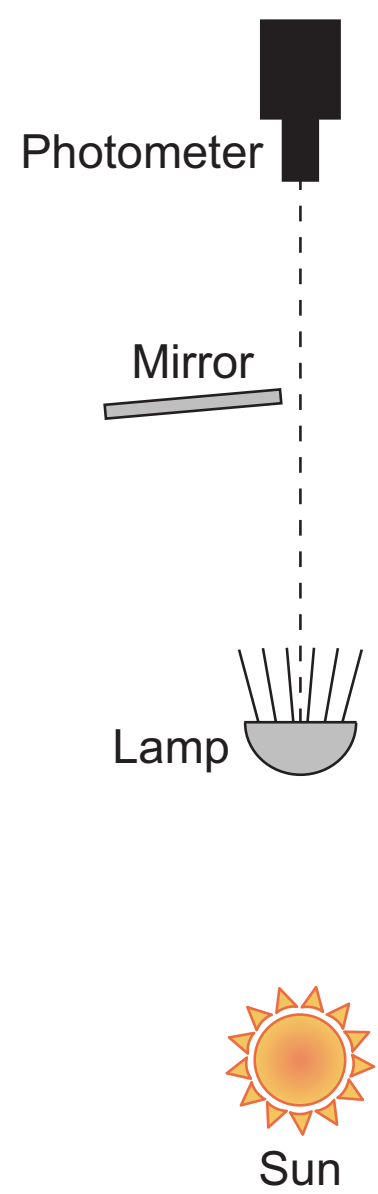

Figure 2. A schematic diagram of the experimental setup (not to scale). 
To minimize stray light from behind each lamp, a large black board $(50 \mathrm{~cm}$ by $80 \mathrm{~cm}$ ) was used to ensure a uniform, dark background. Additionally, to control stray reflections from other parts of the lamp assembly (low or high beams, retroreflectors, trim areas, bezels, etc.), matte black tape was used to mask off the areas adjacent to the turn signal function.

The measurements were made during one week in July 2005, between 11 a.m. and 3 p.m. For the outdoor measurements, each lamp was positioned so that the sun was directly behind the lamp. Vertical illuminance at the surface of each lamp averaged 98,400 lux with the sun reflected into the lamp and 15,600 lux without. For the bulb-on condition, the major filament of each lamp was energized at $12.8 \mathrm{~V}$.

Lamps. All but one of the 20 lamps described above were evaluated. Because of its large aspect ratio, the lamp that was not photometered (for a Chevrolet TrailBlazer), would have required doubling the viewing distance to include it within the $1^{\circ}$ aperture. 


\section{Results}

The ratios of the luminances for the sun on, bulb off vs. sun off, bulb off conditions are described in Table 4. This luminance contrast represents the sun effect. An analysis of variance showed that there were no statistically significant differences among the lamp types, $F(2,16)<1$.

The ratios of the luminances for the sun off, bulb on vs. sun off, bulb off conditions are described in Table 5. This luminance contrast represents the bulb effect without the sun directly hitting the turn-signal lamp. There were no statistically significant differences among the lamp types, $F(2,16)<1$.

Table 4

The sun effect: The ratio of the luminances for the sun on, bulb off vs. sun off, bulb off conditions.

\begin{tabular}{|l|c|c|c|}
\hline \multicolumn{1}{|c|}{ Lamp type } & Minimum & Mean & Maximum \\
\hline \hline Amber lens, lens optics & 1.9 & 4.6 & 11.5 \\
\hline Clear lens, lens optics & 2.2 & 6.5 & 10.7 \\
\hline Clear lens, no lens optics & 2.3 & 7.9 & 28.8 \\
\hline
\end{tabular}

Table 5

The bulb effect without the sun: The ratio of the luminances for the sun off, bulb on vs. sun off, bulb off conditions.

\begin{tabular}{|l|c|c|c|}
\hline \multicolumn{1}{|c|}{ Lamp type } & Minimum & Mean & Maximum \\
\hline \hline Amber lens, lens optics & 11.0 & 19.9 & 26.6 \\
\hline Clear lens, lens optics & 11.4 & 17.3 & 22.8 \\
\hline Clear lens, no lens optics & 9.8 & 19.6 & 27.0 \\
\hline
\end{tabular}


The ratios of the luminances for the sun on, bulb on vs. sun on, bulb off conditions are described in Table 6. This luminance contrast represents the bulb effect with the sun directly hitting the turn-signal lamp. An analysis of variance showed that the effect of lamp type was statistically significant, $F(2,16)=5.6, p<.05$. Post-hoc tests indicate that this luminance contrast was greater for the amber-lens lamps than for either of the clear-lens lamps, but that the difference between the two types of clear-lens lamps was not statistically significant.

Table 7 describes a ratio of two ratios: the luminance contrast representing the bulb effect with the sun (from Table 6) and the luminance contrast representing the sun effect (from Table 4). Thus, the ratio in Table 7 compares the magnitudes of the underlying ratios. An analysis of variance showed that the effect of lamp type was statistically significant, $F(2,16)=6.4, p<.01$. Post-hoc tests indicate that this luminance contrast was greater for the amber-lens lamps than for either of the clear-lens lamps, but that the difference between the two types of clear-lens lamps was not statistically significant.

Table 6

The bulb effect with the sun: The ratio of the luminances for the sun on, bulb on vs. sun on, bulb off conditions.

\begin{tabular}{|l|c|c|c|}
\hline \multicolumn{1}{|c|}{ Lamp type } & Minimum & Mean & Maximum \\
\hline \hline Amber lens, lens optics & 1.9 & 8.4 & 11.6 \\
\hline Clear lens, lens optics & 2.5 & 3.8 & 5.6 \\
\hline Clear lens, no lens optics & 1.9 & 4.4 & 6.8 \\
\hline
\end{tabular}

Table 7

The ratio of the bulb effect with the sun (from Table 6) vs. the sun effect (from Table 4).

\begin{tabular}{|l|c|c|c|}
\hline \multicolumn{1}{|c|}{ Lamp type } & Minimum & Mean & Maximum \\
\hline \hline Amber lens, lens optics & 0.2 & 3.6 & 6.0 \\
\hline Clear lens, lens optics & 0.2 & 0.8 & 2.5 \\
\hline Clear lens, no lens optics & 0.1 & 1.0 & 2.9 \\
\hline
\end{tabular}




\section{Implications for driver performance}

\section{Desirable level of luminance contrast}

In Sivak et al. (1998), we addressed the issue of determining a reasonable minimum luminance contrast for a signal by examining three different sources of information: basic laboratory studies on luminance threshold, a field study on just noticeable differences for automobile signal lamps, and the current SAE standard for intensity ratio of signal lamps that provide two different functions.

The data from basic laboratory studies indicate that to detect a luminance increment over a uniform background, the increment needs to be approximately equal to a constant proportion of the background luminance. This relation is known as Weber's Law (e.g., Coren, Porac, and Ward, 1979). Formally, Weber's Law states that $\Delta L=K L$, where $\Delta L$ is the magnitude of the increment at threshold, $L$ is the background luminance, and $K$ is a constant. Although the precise value of $K$ depends on a variety of factors, including the duration of the exposure and the age of the observer, a reasonable value for $K$ in the fovea is 0.08 (or $8 \%$ ) (Teghtsoonian, 1971). In other words, in well-controlled laboratory studies, subjects' threshold for a detectable increment in luminance is about $8 \%$ over the background luminance (regardless of the absolute level of the background luminance). The threshold increment can, in turn, be used to estimate the necessary luminance increment for sufficient suprathreshold visibility (or conspicuity). Although there is no general agreement on this issue, there is evidence that an increase in $\Delta L$ by at least a factor of 10 over the threshold value is needed for sufficient visibility under demanding conditions (e.g., Adrian, 1993). Using the factor of 10 would result in an increment of about $80 \%$, or a contrast of 1.8 between the stimulus and its background.

Huey, Dekker, and Lyons (1994) investigated the just noticeable differences in the brightness of two simultaneously presented stimuli representing automobile signal lamps. (Two viewing distances were used. Judging from a schematic diagram in the report, the resulting gaps between the two light-emitting surfaces were about $0.2^{\circ}$ and $1.0^{\circ}$, respectively.) The results indicate that, on average, subjects required the intensities to differ by about $25 \%$ for the stimuli to be noticeably different. If we, again, apply a 
factor of 10 to move from threshold difference to a reasonable visibility level (Adrian, 1993), we obtain a difference of $250 \%$, or a contrast of 3.5 between the two stimuli.

The SAE standard for turn-signal lamps (SAE, 2000), and, by reference to the SAE standard, also the current U.S. regulations (FMVSS, 2004), provide additional guidance for a reasonable luminance contrast. The SAE standard states the following:

When a tail lamp or parking lamp is combined with the turn signal lamp, the signal lamp shall not be less than three times the luminous intensity (a) of the tail lamp at any test point, or (b) of the parking lamp at any test point on or above horizontal except that at $\mathrm{H}-\mathrm{V}, \mathrm{H}-5 \mathrm{~L}, \mathrm{H}-5 \mathrm{R}$, and $5 \mathrm{U}-\mathrm{V}$, the signal lamp shall not be less than five times the luminous intensity of the tail lamp or parking lamp. (SAE, 2000, §6.1.5.3)

Although the SAE standard refers to the situation where two signals are being conveyed by the same light-emitting surface, the sun-loading effect under consideration in the present study is somewhat analogous. Consequently, the SAE standard has potential relevance to the present situation.

In summary, the results of basic laboratory studies, coupled with the use of a factor of 10 between a threshold increment and a reasonable level of suprathreshold visibility, indicate that to achieve a reasonable level of visibility, the luminance contrast between the on and off states for foveal stimuli needs to be at least 1.8. Analogously, field research on just noticeable differences in lamp brightness (coupled, again, with the use of a factor of 10 between threshold and suprathreshold visibility) yields, for stimuli in near periphery, a minimum contrast of 3.5. Finally, the current SAE standard for signal lamps that use different signals from the same light-emitting surface calls for a contrast factor of 5 (at the observation angle of $\mathrm{H}, \mathrm{V}$ ) between the two signals. Which of these contrasts should we use as a guideline for evaluating the luminance contrast obtained in the present study between the on and off states of turn signals? The minimum contrast derived from laboratory studies is likely to be too small for real-world situations requiring simultaneous performance of another task, such as driving. Therefore, the other two recommendations (3.5 and 5) are more realistic. 


\section{Detecting turn signals in direct sunlight}

The luminance contrast for sun on, bulb on vs. sun on, bulb off influences the detectability (the frequency of hits or correct detections) of turn signals in direct sunlight. Table 6 (on page 8) summarizes the relevant results. There are five main findings in Table 6. First, the relevant luminance contrast (sun on, bulb on vs. sun on, bulb off) was greater for the amber-lens lamps (mean of 8.4) than for the clear-lens lamps (means of 3.8 and 4.4). Second, the luminance contrast did not differ between the two types of clear-lens lamps. Third, the mean luminance contrast for each of the three lamp types exceeded 3.5 (the more liberal of the two criteria derived above). Fourth, the minimum contrast value was less than 3.5 for each lamp type (1.9, 2.5, and 1.9, respectively). Fifth, the maximum luminance contrast for each of the three lamp types exceeded 5 (the more conservative of the two criteria derived above).

Overall, the data in Table 6 indicate that although the relevant luminance contrast for detecting turn signals tends to be smaller for clear-lens lamps than for amber-lens lamps, clear-lens lamps can be designed to provide sufficient luminance contrast.

\section{Differentiating between turn signals and sun reflections}

Even if the luminance contrast for sun on, bulb on vs. sun on, bulb off is sufficiently large, transient sun reflections can cause problems by being mistakenly identified as turn signals (sun phantoms). Such false alarms might happen if the luminance contrast for sun on, bulb off vs. sun off, bulb off was comparable in magnitude to the luminance contrast for sun on, bulb on vs. sun on, bulb off. The data in Table 7 (on page 8) are relevant to the ease of differentiating between turn signals and sun reflections. There are three main findings in Table 7. First, on average, the luminance contrast due to the bulb was 3.6 times the luminance contrast due to the sun for the amber-lens lamps; the corresponding ratios were only 0.8 and 1.0 for the clear-lens lamps. Second, there was no difference between the two types of clear-lens lamps on this measure. Third, for each lamp type, there were luminance contrasts due to the bulb that were smaller than the

luminance contrasts due to the sun (the ratios of the contrasts were less than 1). The smallest ratios among the three lamp types were $0.2,0.2$, and 0.1 , respectively. 
Overall, the data in Table 7 indicate that the ratio of the bulb effect vs. sun effect tended to be greater for amber-lens lamps than for clear-lens lamps. However, the smallest ratios were substantially less than 1 for both types of lamps. These results suggest that, although clear-lens lamps are more susceptible than amber-lens lamps to sun phantoms, there is wide variation within each lamp type.

\section{What does it all mean: Four illustrative examples}

Let us consider four examples (see Table 8). In Example 1, the bulb effect in the sun is relatively large, and it is also relatively large in relation to the sun effect. This condition is predicted to lead to a high level of hits (correct detections of turn signals) and a low level of false alarms (mistaken identifications of sun reflections as turn signals). In Example 2, the bulb effect in the sun is relatively large, but it is relatively small in relation to the sun effect. This condition is predicted to lead to a high level of hits but also a high level of false alarms. In Example 3, the bulb effect in the sun is relatively small, and it is also relatively small in relation to the sun effect. This condition is predicted to lead to a low level of hits and a high level of false alarms. In Example 4, the bulb effect in the sun is relatively small, but it is relatively large in relation to the sun effect. This condition is predicted to lead to a low level of hits but also a low level of false alarms.

Table 8

Four illustrative example of the effectiveness of turn signals,

\begin{tabular}{|c|c|c|c|c|}
\hline Example & $\begin{array}{c}\text { Bulb effect in the } \\
\text { sun (Table 6) }\end{array}$ & $\begin{array}{c}\text { Ratio of the bulb effect } \\
\text { in the sun and the sun } \\
\text { effect (Table 7) }\end{array}$ & $\begin{array}{c}\text { Predicted level } \\
\text { of hits }\end{array}$ & $\begin{array}{c}\text { Predicted } \\
\text { level of false } \\
\text { alarms }\end{array}$ \\
\hline \hline 1 & 5 & 2.5 & High & Low \\
\hline 2 & 5 & 1 & High & High \\
\hline 3 & 2 & 1 & Low & High \\
\hline 4 & 2 & 2.5 & Low & Low \\
\hline
\end{tabular}




\section{Indirect benefits for turn signals that are near low-beam headlamps}

It is generally recognized in regulations that headlamp illumination can negatively influence the detectability of nearby turn signals. For example, the U.S. requirements (FMVSS, 2004) state that the minimum intensity for turn signals that are less than $10 \mathrm{~cm}$ from low beam headlamps (center to edge) needs to be 2.5 times the minimum intensity for turn signals located farther away. It follows that turn signals that are near low beams should perform better in direct sun. This is because they are likely to provide greater bulb effects in the sun and greater ratio of the bulb effect in the sun vs. the sun effect. Indeed, this hypothesis was supported by the present data (see Table 9).

Table 9

Effectiveness of turn signals in direct sun as an indirect function of the proximity to low beam headlamps. (Larger entries are better.)

\begin{tabular}{|l|c|c|}
\hline \multirow{2}{*}{ Measure } & \multicolumn{2}{|c|}{ Turn signal to headlamp separation } \\
\cline { 2 - 3 } & $<10 \mathrm{~cm}$ & $\geq 10 \mathrm{~cm}$ \\
\hline \hline Mean bulb effect in the sun (Table 6) & 5.2 & 4.0 \\
\hline $\begin{array}{l}\text { Mean ratio of the bulb effect in the sun } \\
\text { and the sun effect (Table 7) }\end{array}$ & 1.6 & 0.6 \\
\hline
\end{tabular}




\section{Conclusions}

Current front turn-signal lamps in the U.S. predominantly use clear lenses and amber bulbs. However, clear-lens lamps are more susceptible than amber-lens lamps to sun reflections that may be interpreted as turn signals (sun phantoms). In this study, we quantified the relevant photometric differences in direct sunlight between these two lamp types for a large sample of current lamps, and presented inferences for likely effects on driver performance.

Although our data confirm that, in general, clear-lens lamps are likely to provide signals that are less discriminable, the variability within each lamp type is large. In other words, some clear-lens turn lamps currently on the road are likely to be resistant to sun phantoms, and some amber-lens lamps are not.

The report also discusses the desirable photometric levels of turn signals for effective performance in direct sunlight. Finally, it is argued that an indirect benefit of turn-signal lamps that are near low-beam headlamps is that, because of their higher required intensities, they are likely to be less susceptible to sun phantoms than lamps farther away from low beams. 


\section{References}

Adrian, W. (1993). The physiological basis of the visibility concept. In, Proceedings of the 2 nd international symposium on visibility and luminance in roadway lighting (pp. 17-30). New York: Lighting Research Institute.

Automotive News. (2004, January 12). Detroit: Crain Communications.

Coren, S., Porac, C., and Ward, L.M. (1979). Sensation and perception. New York: Academic Press.

FMVSS [Federal Motor Vehicle Safety Standards]. (2004). Standard No. 108; Lamps, reflective devices, and associated equipment. In Code of Federal Regulations, Title 49 (Part 571.108). Washington, D.C.: Office of the Federal Register.

Huey, R., Dekker, D., and Lyons, R. (1994). Driver perception of just-noticeable differences of automotive signal lamp intensities (Report No. DOT HS 808 209). Washington, D.C.: National Highway Traffic Safety Administration.

SAE [Society of Automotive Engineers]. (2000). Turn signal lamps for use on motor vehicles less than $2032 \mathrm{~mm}$ in overall width (SAE Standard J588). Warrendale, PA: Society of Automotive Engineers.

Sivak, M., Flannagan, M.J., Kojima, S., and Traube, E.C. (1998). The influence of sun loading on the visibility of clear-lens turn signals (Report No. UMTRI-98-2). Ann Arbor: The University of Michigan Transportation Research Institute.

Sullivan, J. and Flannagan, M.J. (2001). Reaction time to clear-lens turn signals under sun-loaded conditions (Report No. UMTRI-2001-30). Ann Arbor: The University of Michigan Transportation Research Institute.

Teghtsoonian, R. (1971). On the experiments in Stevens' Law and the constant in Ekman's Law. Psychological Review, 78, 71-80. 